\title{
Aliança terapêutica em psicoterapia de orientação psicanalítica: aspectos teóricos e manejo clínico
}

\section{Therapeutic alliance in psychoanalytic psychotherapy: theoretical aspects and clinical handling}

\author{
Rodrigo Sanches PERES
}

\begin{abstract}
Resumo
O termo aliança terapêutica, de utilização cada vez mais frequente na literatura psicanalítica, muitas vezes é equiparado erroneamente à transferência positiva ou considerado o oposto da transferência negativa. Trata-se, porém, de um termo com importantes especificidades. Este estudo objetivou abordar aspectos teóricos da aliança terapêutica e discutir seu manejo no contexto da psicoterapia de orientação psicanalítica. Para tanto, envolveu uma revisão bibliográfica e uma discussão de vinheta clínica. A revisão bibliográfica subsidiou o entendimento da aliança terapêutica como uma relação de trabalho, influenciada tanto por elementos conscientes quanto por conteúdos inconscientes, que se estabelece entre paciente e psicoterapeuta em prol do processo psicoterapêutico. A partir da discussão de vinheta clínica, o papel da escuta empática, da atitude amistosa, da atividade clarificadora, da função sintética e da postura reflexiva do psicoterapeuta para promovê-la e sustentá-la são enfatizados.
\end{abstract}

Unitermos: Aliança terapêutica. Psicologia clínica. Psicoterapia.

\begin{abstract}
The term "therapeutic alliance",employed more and more frequently in psychoanalytic literature, is usually compared, albeit erroneously, to positive transference or regarded as the opposite of negative transference. It is, however, a term with significant specificities. The present study aims to deal with theoretical aspects of the therapeutic alliance and to discuss its handling in the context of psychoanalytic psychotherapy. To this end, the present study involves a bibliographical review and a discussion of a clinical case. The bibliographical review supports the understanding of therapeutic alliance as a work relationship, influenced by both conscious elements and unconscious content, which is established between patient and psychotherapist in support of the psychotherapeutic process. The clinical case discussion emphasizes the role of the psychotherapist: comprehensive listening, friendly attitude, explanatory activity, synthetic function and reflexive posture to promote and sustain the therapeutic alliance.
\end{abstract}

Uniterms: Therapeutic alliance. Clinical psychology. Psychotherapy.

Freud afirmou, quando da publicação de seus revolucionários estudos sobre a teoria e a clínica da histeria, que seria necessário transformar o paciente em colaborador para que se pudessem superar as resis- tências que, durante o processo psicoterapêutico, inconscientemente se impõem às lembranças das experiências infantis e, assim, obliteram o acesso aos resíduos da sexualidade pré-genital. Ademais, advertiu

\footnotetext{
$\boldsymbol{\nabla \nabla v \nabla}$

1 Universidade Federal de Uberlândia, Instituto de Psicologia. Av. Pará, 1720, Bloco 2 C, Campus Umuarama, 38405-320. Uberlândia, MG, Brasil. E-mail: $<$ rodrigosanchesperes@yahoo.com.br>.
} 
que um obstáculo a essa transformação surge com o estabelecimento de uma falsa ligação do paciente com o psicoterapeuta, que seria motivado por um fenômeno que recebeu o nome de "transferência" (Freud, 1893/1996a)

Obviamente a transferência passou a ser entendida de forma mais ampla pelo pai da psicanálise após a virada do século XIX. Esse fato torna-se claro levando-se em consideração que Freud a concebeu como um importante "agente terapêutico" no clássico historial clínico do Homem dos Ratos (Freud, 1909/1996b). Além disso, em um momento posterior sua teorização sobre o assunto foi refinada com a proposição de uma proveitosa divisão do fenômeno transferencial em dois tipos básicos: negativo e positivo. O primeiro seria resultado do predomínio de pulsões agressivas e seus derivados na reedição de experiências prévias do paciente com o psicoterapeuta (Freud, 1913/1996c). O segundo, em contraste, decorreria da influência majoritária de pulsões libidinais.

Contudo, a transferência positiva ocorreria, conforme a concepção freudiana, não apenas mediante a atualização de sentimentos amistosos admissíveis à consciência, mas também em função da revivescência de seus prolongamentos inconscientes. Não sendo executado o manejo técnico apropriado, a transferência positiva tenderia a evoluir para um vínculo erotizado e, assim, desempenhar um papel negativo no curso do processo psicoterapêutico, ensejando o que autores contemporâneos têm descrito como "conluio transferencial-contratransferencial" ou "recíproca fascinação narcisista" (Zimerman, 2001).

Vale destacar ainda que, paradoxalmente, o desenvolvimento da transferência negativa pode ser oportuno. Afinal, seus desdobramentos, quando ressignificados sob a ótica da neurose de transferência - ou seja, a "neurose artificial", que promove uma completa reorganização da psicopatologia do paciente em sua relação com o psicoterapeuta (Freud, 1914/1996d) - são capazes de subsidiar a elaboração de fantasias arcaicas, associadas, por exemplo, à destrutividade ou à inveja. Conclui-se, portanto, que, como esclarecem Laplanche e Pontalis (2000), a valência positiva ou negativa dos sentimentos transferidos não determina com precisão suas repercussões clínicas.

\section{Aliança terapêutica regressão terapêutica}

O termo "aliança terapêutica", de utilização cada vez mais frequente na literatura psicanalítica, muitas vezes é equiparado erroneamente à transferência positiva ou considerado o oposto da transferência negativa. Porém, como alerta Etchegoyen (2004, p.141), no processo psicoterapêutico "a transferência está em tudo, mas nem tudo o que existe é transferência". Indubitavelmente a aliança terapêutica representa um dos aspectos do vínculo transferencial em seu sentido mais abrangente. Mas o que a caracteriza? De que maneira ocorre seu estabelecimento no contexto da psicoterapia de orientação psicanalítica? Este estudo teve como objetivo tratar dessas questões mediante uma revisão teórica e uma discussão de vinheta clínica.

O mérito de definir o termo "aliança terapêutica" é atribuído à psicanalista norte-americana Elisabeth Zetzel. A autora em pauta o concebe basicamente como uma relação de trabalho que se estabelece entre paciente e psicoterapeuta em prol do processo psicoterapêutico. Tal relação se assenta nas funções autônomas do ego do primeiro, mas remete às suas relações objetais infantis. Desse modo, também depende da capacidade do segundo de demonstrar empatia e respeito, fornecendo, assim, parâmetros para a ocorrência de uma identificação consistente a ponto de neutralizar as forças instintivas que ressurgem com a transferência (Zetzel, 1956).

Tendo em vista o que precede, constata-se que, a despeito de não ser freudiano, o termo "aliança terapêutica" tem suas raízes na teorização do pai da psicanálise. Afinal, Freud (1913/1996c, p.157) afirmou que:

permanece sendo o primeiro objetivo do tratamento ligar o paciente a ele mesmo e à pessoa do médico. ... Se se demonstra um interesse sério nele, se cuidadosamente se dissipam as resistências que vêm à tona no início e se evita cometer certos equívocos, o paciente por si próprio fará essa ligação e vinculará o médico a uma das imagos das pessoas por quem estava acostumado a ser tratado com afeição. É certamente possível sermos privados deste primeiro sucesso se, desde o início, assumirmos outro ponto de vista que não o da compreensão.

Justamente nesse sentido, Etchegoyen (2004) defende que a aliança terapêutica, em contraste com a 
transferência, decorre da atualização de experiências prévias do paciente que o ajudam a se situar no presente, em vez de levá-lo a simplesmente repetir o passado no âmbito da relação psicoterapêutica. Porém, cumpre assinalar que a aliança terapêutica, na concepção da autora que a descreveu originalmente, possui elementos racionais e componentes irracionais, como a consciência da necessidade de receber assistência profissional para encontrar alívio para o próprio sofrimento emocional, por um lado, e o desejo de encontrar esse alívio sem empreender maiores esforços, por outro.

As diferenças entre a aliança terapêutica e a neurose de transferência ancoram-se basicamente em um parâmetro temporal, uma vez que a primeira pode ser considerada um pré-requisito da segunda. Conforme Zetzel (1956), a eclosão da neurose de transferência depende da regressão terapêutica, ou seja, do movimento psíquico que, nos primeiros meses do processo psicoterapêutico, viabiliza a reabertura de conflitos fundamentais e enseja a recirculação de energia instintiva. Tal movimento, vale destacar, não conduz o paciente a um mero retorno a etapas anteriores de seu desenvolvimento emocional. Ao contrário, oferece-lhe uma possibilidade ímpar de elaborar problemáticas arcaicas, pois não afeta as funções autônomas do ego.

\section{Aliança terapêutica e dissociação terapêutica do ego}

De que forma a aliança terapêutica está relacionada à regressão terapêutica? A resposta de Zetzel (1956) a essa questão demanda a menção a um termo ao qual a autora em pauta conferiu um significado original: dissociação terapêutica do ego. Forjado por Sterba (1934), esse termo diz respeito a um fenômeno que leva uma parte do aparelho psíquico do paciente, orientada à realidade externa, a se opor à outra parte, influenciada por resistências inconscientes, e colaborar com o psicoterapeuta de modo a favorecer uma posterior síntese egoica. A parte colaborativa do aparelho psíquico funcionaria, portanto, como um filtro através do qual passaria todo o material transferencial.

Sterba (1934) sublinhou que a interpretação do psicoterapeuta - sobretudo a interpretação transferencial - é imprescindível para que ocorra uma consistente identificação do paciente com o processo psicoterapêutico e, em um segundo momento, para que se implemente a dissociação terapêutica do ego. Já Zetzel (1956) defendia que a dissociação terapêutica do ego depende basicamente da regressão terapêutica que, por sua vez, somente ocorrerá se o paciente apresentar um ego suficientemente maduro e, assim, mostrar-se capaz de depositar no psicoterapeuta uma confiança básica, análoga àquela que permite ao bebê tolerar sua dependência da figura materna.

O paciente deve, seguindo esse raciocínio, ser flexível a ponto de autorizar uma diminuição parcial, temporária e controlada das funções autônomas do ego para que conteúdos inconscientes venham a atingir a consciência sem provocar uma irrupção maciça do processo primário. Como resultado disso, o paciente poderia, com a parte colaborativa de seu aparelho psíquico que aderiu previamente à aliança terapêutica, compreender a natureza irracional da parte defensiva de seu aparelho psíquico que, movida pelas forças do id e pelos imperativos do superego, coloca obstáculos ao processo psicoterapêutico (Gomes, 2005).

Ao contrário do que se poderia supor a partir de uma leitura superficial, Zetzel (1956) defende que tanto a aliança terapêutica quanto a regressão terapêutica - e, consequentemente, a dissociação terapêutica do ego - envolvem apenas a mobilização de recursos internos conquistados pelo paciente em um período anterior à instalação da triangulação edípica, e não uma área livre de conflitos em seu aparelho psíquico. Tais recursos podem ser observados, ainda que em latência, até mesmo em crianças ou em indivíduos cuja personalidade se encontra psicoticamente organizada, mas sua inexistência pode ser entendida como uma incontornável contraindicação ao processo psicoterapêutico.

Posteriormente, a autora em pauta esclareceu que sugeriu, "... como premissa maior dessa discussão, que a relação de objeto primeira e mais significativa ocorre na relação precoce mãe-criança. A natureza e a qualidade dessa conquista precoce relacionam-se com a iniciação da autonomia secundária do ego" (Zetzel, 1965, p.48). Logo, trata-se de uma ousada tentativa de conciliação entre duas vertentes teóricas em psicanálise que se criticavam reciprocamente de modo passional na época: a Psicologia do Ego, de Heinz Hartmann, e a Teoria das Relações Objetais, de Melanie Klein. 


\section{Vinheta clínica}

Fábio (nome fictício), 19 anos, solteiro, acadêmico de História, buscou assistência junto à clínica-escola de psicologia de sua universidade queixando-se de ataques de ansiedade generalizada e pal pitações súbitas. Antes disso, havia se consultado, conforme as orientações de sua irmã primogênita, com três psiquiatras, que rapidamente o diagnosticaram como portador de transtorno do pânico e lhe receitaram psicofármacos. Contudo, Fábio rejeitou o tratamento psiquiátrico porque, segundo ele mesmo referiu, queria entender o que se passava com sua mente, e não se tornar um escravo de remédios.

Fabio informou que perdeu seu pai aos 11 anos de idade e que não sofreu muito com isso porque, na verdade, nunca pôde contar com o mesmo. Devido às constantes viagens a trabalho, seu pai pouco permanecia em casa. Sua mãe tinha uma saúde frágil e apresentava um longo histórico de doenças. A única pessoa em quem depositava confiança e buscava suporte emocional era sua irmã, considerada por ele uma pessoa ponderada e inteligente. Fábio somente se permitia relacionamentos com pessoas nas quais identificava essas características. O seguinte diálogo, estabelecido ao final da primeira sessão de triagem, exemplifica os expedientes utilizados por ele para sondar o psicoterapeuta.

Fábio: Então, o que você acha que eu tenho?

Psicoterapeuta: Penso que ainda é cedo para concluir.

Fábio: Mas você não tem nem ideia?

Psicoterapeuta:Tenho algumas hipóteses, só que precisamos conversar um pouco mais. Podemos marcar outra sessão para o final da semana?

Fábio: Antes eu preciso saber o que você pensa sobre o meu problema.

Psicoterapeuta: Parece que você não se sentirá seguro comigo se eu não te falar o que eu estou pensando agora sobre o seu problema. Mas você se queixou dos psiquiatras que diagnosticaram transtorno do pânico sem te ouvir direito.

Fábio: É verdade, eu achei que eles se precipitaram muito.

Psicoterapeuta: Em psicoterapia a gente trabalha de outra forma. Geralmente são duas ou três sessões para que se possa entender bem o caso.
Fábio: Ah, eu não sabia. Então quer dizer que o meu caso não é tão atípico? Não é tão grave?

Psicoterapeuta: O que fica claro desde já é que você pode se beneficiar da assistência que a gente oferece aqui, principalmente porque você se mostra muito interessado em se entender e em melhorar.

Fábio: É, eu quero melhorar mesmo. Para quando a gente pode marcar a outra sessão?

Apesar de esse diálogo sugerir que a dificuldade para estabelecer vínculos de Fábio se destacava como a contrapartida emocional de sua queixa manifesta, o que se pretende basicamente éilustrar como identificações projetivas transferenciais fizeram com que o mesmo revivenciasse com o psicoterapeuta, já na primeira sessão de triagem, aspectos importantes de suas experiências prévias, ensejando uma sensação de desamparo e, concomitantemente, uma atitude de desconfiança. Ademais, esse diálogo evidencia a importância da adoção de uma escuta empática e do emprego de intervenções clarificadoras e reforçadoras - a exemplo, respectivamente, das duas últimas intervenções do psicoterapeuta - para criar as bases de uma aliança terapêutica a ser efetivamente selada nas sessões subsequentes.

Também pode ser vislumbrada a necessidade do psicoterapeuta de assumir uma postura reflexiva para oportunamente se dirigir à parte do aparelho psíquico do paciente que se mostra, de antemão, disposta a estabelecer uma relação de trabalho, e não interpretá-la precipitadamente. No diálogo em pauta, isso ocorreu graças à segunda e à terceira intervenções do psicoterapeuta. Fábio então se mostrou capaz, apoiando-se em suas funções autônomas do ego, de dar os primeiros passos rumo a uma relação objetal distinta daquela que estabelecera com seu pai, e semelhante, em seus aspectos positivos, àquela que sustentava com sua irmã. Nessas circunstâncias, o paciente, como bem observou Gomes (2005), embora sinta o passado no presente, diferencia-o da "relação terapêutica real".

Na segunda sessão de triagem o contrato terapêutico foi cuidadosamente executado e Fábio passou a ser atendido em psicoterapia de orientação psicanalítica duas vezes por semana. Em poucos meses a aliança terapêutica tornou-se consistente a ponto de favorecer a regressão terapêutica. O paciente percebeu que, com 
o suporte do psicoterapeuta, poderia, sem provocar uma invasão afetiva desestruturante, abrir mão provisoriamente de estratégias defensivas que não possibilitavam o acesso a certos conteúdos inconscientes. Procedendo desta forma, verificou a irracionalidade desses conteúdos, o que implementou a dissociação terapêutica do ego.

No início do segundo ano de psicoterapia, o primeiro encontro fortuito fora do contexto da clínica-escola levou ao auge da neurose de transferência. Esse encontro, vale destacar, ocorreu durante um evento científico multidisciplinar do qual ambos estavam participando. O psicoterapeuta conversava com o professor universitário responsável na época pela orientação de uma pesquisa que vinha sendo desenvolvida pelo paciente. Aproximando-se visivelmente constrangido, o paciente cumprimentou apenas seu orientador, mas manteve contato visual com o psicoterapeuta por alguns segundos. Na sessão seguinte, esse fato foi abordado e elaborado, como se vê no seguinte diálogo.

Fábio: Nossa, foi estranho ver você conversando com o meu orientador lá no congresso. Eu não sabia o que fazer. Eu ia desviar para não passar perto de vocês, mas aí mudei de ideia.

Psicoterapeuta: O que te levou a mudar de ideia?

Fábio: Então, é bobeira... Mas de repente eu fiquei curioso para saber do que vocês estavam conversando.

Psicoterapeuta: Você achou que poderia ser sobre você?

Fábio: É... Por um instante eu cheguei a pensar que poderia ser. Só que eu peguei uma parte da conversa e vi que não era isso. Você apresentou um trabalho que tem a ver com uma linha de pesquisa dele, né? ... Às vezes é ruim essa encanação que eu tenho, essa desconfiança das pessoas.

Psicoterapeuta: Lembra que logo em uma das primeiras sessões a gente conversou sobre isso? Eu te falei que você poderia sentir isso em relação a mim também.

Fábio: É, na hora eu até achei que não tinha nada a ver uma coisa com a outra.

Psicoterapeuta: Tem, mas ao mesmo tempo não tem, você não acha?
Fábio: Acho que sim. É estranho porque é diferente. Não é aquela desconfiança terrível, é só uma pulga atrás da orelha que aparece de vez quando.

Psicoterapeuta: Você precisou ouvir o que eu estava conversando com ele para ter certeza de que a gente não estava falando de você. Mas em outras situações na sua vida, com outras pessoas, você não conseguiu suportar essa desconfiança. Isso te levou a se isolar muito. Então eu acho que você está progredindo nesse sentido.

\section{Discussão}

Conforme Ceitlin e Cordioli (1998), o psicoterapeuta cria condições propícias para que a aliança terapêutica possa ser estabelecida nas primeiras sessões, oferecendo ao paciente a possibilidade de se expressar o mais livremente possível, não se deixando perturbar com suas revelações e sendo cuidadoso em não emitir julgamentos ou conclusões precipitadas. Todas as intervenções do psicoterapeuta no primeiro diálogo apresentado na vinheta clínica ilustram essas proposições. Posteriormente, ainda de acordo com os autores em pauta, a aliança terapêutica se fortalece quando o psicoterapeuta emprega intervenções reasseguradoras e reconhece os progressos do paciente, a exemplo do que ocorreu com a última intervenção no segundo diálogo apresentado na vinheta clínica.

Como bem observam Eizirik, Liberman e Costa (1998), a aliança terapêutica também se encontra intimamente associada à "relação terapêutica real", que, por sua vez, tem como ponto de partida principal para o paciente características pessoais do psicoterapeuta evidenciadas quando da execução do contrato terapêutico e da definição de regras aceitáveis para ambas as partes sobre frequência, horário, duração, faltas, atrasos, sigilo, férias e honorários. Comunicar tais regras ao paciente com clareza, serenidade e sensibilidade é um imperativo para minimizar distorções transferenciais, bem como enfatizar desde o início que o paciente necessita assumir a iniciativa das sessões e gradativamente desenvolver o hábito da auto-observação.

A aliança terapêutica tende a se tornar mais intensa com o andamento do processo psicoterapêutico caso tenha sido estabelecida uma "relação 
terapêutica real" de valência positiva. Não obstante, é inevitável que, como revelou o fato abordado interpretativamente ao longo do segundo diálogo apresentado na vinheta clínica, a transferência se faça presente com intensidade em determinados momentos, aproximando a aliança terapêutica da neurose de transferência. Para Etchegoyen (2004), impõe-se nessas circunstâncias o cuidadoso manejo de um importante aspecto do vínculo psicoterapêutico: a assimetria. No contexto da neurose de transferência, a assimetria deve ser entendida como uma consequência da diferença de papéis que desempenham paciente e psicoterapeuta no processo psicoterapêutico.

O referido autor esclarece que a assimetria não pressupõe a existência de qualquer supremacia, apenas demarca os polos do vínculo psicoterapêutico. Quando da eclosão da neurose de transferência, negligenciá-los será contraproducente. Contudo, utilizá-los no contexto da "relação terapêutica real" é um procedimento autoritário, prejudicial não apenas à capacidade de juízo do paciente, mas, sobretudo, à continuidade da aliança terapêutica. Não se deve perder de vista que a aliança terapêutica funda-se na simetria inerente a qualquer relação humana que se estabelece entre duas pessoas reais igualmente adultas.

Para possibilitar uma discussão mais abrangente do manejo clínico da aliança terapêutica, justificam-se ainda algumas ponderações sobre os casos considerados "difíceis". Dentre os diversos tipos de pacientes agrupados sob essa rubrica, parece particularmente proveitoso destacar aqueles cuja organização da personalidade, devido à ocorrência de perturbações do senso de identidade e à prevalência de mecanismos de defesa primitivos, pode ser categorizada como borderline. Afinal, tais pacientes não são a priori contraindicados à psicoterapia de orientação psicanalítica, o que, para Gabbard (2005), difere-os da maioria daqueles que, além das referidas características, apresentam um grave prejuízo do teste de realidade e, por esse motivo, podem ter a organização da personalidade categorizada como psicótica.

A qualidade da aliança terapêutica com pacientes borderline frequentemente é afetada, conforme Schestatsky (2005), pela mais clara manifestação da tendência à cisão dos objetos internos que lhes é típica, a saber: a equivalente cisão dos objetos externos. Esse fenômeno fomenta uma acentuada propensão à violação do contrato terapêutico, dado que implica imprevisíveis reversões de atitudes para com o psicoterapeuta. Como ressalta o autor em pauta, o manejo clínico dessas situações - bem como, em um sentido mais amplo, a definição das estratégias de tratamento desses pacientes - depende essencialmente de como se compreendem as origens da psicopatologia borderline.

Na perspectiva psicodinâmica, o modelo conflitual/intrapsíquico opõe-se ao modelo deficitário/interpessoal. Adeptos do primeiro modelo sustentam que o estabelecimento e o fortalecimento da aliança terapêutica com pacientes borderline envolvem a exploração, via interpretação transferencial, de fantasias inconscientes, mecanismos de defesa primitivos e distorções perceptuais demonstradas pelo paciente devido à ativação de relações objetais dissociadas e internalizadas. Tal processo deve começar a ser empreendido durante a execução do contrato terapêutico para que comportamentos desadaptativos possam ser prevenidos. Ademais, considera-se prioritário o exame imediato de qualquer tentativa de desvirtuar os fatores de enquadre (Kernberg, 2005).

Por outro lado, autores que se alinham ao segundo modelo recomendam uma atitude distinta por entenderem que pacientes borderline exigem uma preparação especial para se beneficiarem de interpretações transferenciais, que se estabelecem graças ao recurso prévio do psicoterapeuta a intervenções de apoio capazes de assegurar-Ihes uma mínima introjeção de objetos bons (Gabbard, 2004/2005). Em suma: a formulação de interpretações transferenciais anteriores ao alívio da hostilidade em relação ao psicoterapeuta é vista como uma séria ameaça à aliança terapêutica, e não como um pré-requisito da execução do contrato terapêutico. Consequentemente, é usual a opção por definir o contrato terapêutico mais pormenorizadamente à medida que surgem situações que colocam à prova as combinações iniciais.

A despeito da articulação dessas diretrizes gerais às concepções etiológicas que as fundamentam, deve-se enfatizar que, como bem observou Schestatsky (2005), a prescrição de tratamentos-padrão para pacientes borderline em termos da especificidade de intervenções interpretativas ou suportivas não se sustenta porque os mesmos não constituem uma 
população homogênea. Somando-se a esse fato irrefutável, vale mencionar que não há evidências de que qualquer psicoterapia possa se desenvolver satisfatoriamente sem uma transição - determinada, sobretudo, pelo material que está sendo trabalhado durante as sessões - do extremo expressivo ao extremo apoiador do espectro classicamente adotado para a diferenciação das verbalizações do psicoterapeuta.

É possível identificar um ponto de convergência entre representantes do modelo conflitual/intrapsíquico e do modelo deficitário/interpessoal. Ambos reconhecem que o principal desafio técnico a ser superado na psicoterapia de orientação psicanalítica com pacientes borderline é o desenvolvimento de respostas adequadas às perturbadoras emoções desencadeadas precocemente a partir da interação com os mesmos. Cabe ao psicoterapeuta, portanto, permanecer especialmente atento às manifestações contratransferenciais de ansiedade, raiva, culpa ou impotência, frequentes desde o primeiro contato com o indivíduo (Schestatsky, 2005). Somente assim acting-outs capazes de tornar insustentável a aliança terapêutica poderão ser evitados.

\section{Considerações Finais}

Pautando-se nos fundamentos epistemológicos estabelecidos por Zetzel, diversos autores apresentaram contribuições próprias ao entendimento da aliança terapêutica. Termos derivados foram criados a partir disso, tais como "aliança de trabalho", por Ralph Greenson, e "transferência racional", por Otto Fenichel. Não obstante, a aliança terapêutica, tal como definida originalmente, ainda se impõe como uma variável central do processo psicoterapêutico. Portanto, é possível entendê-la não apenas como um critério de indicação para psicoterapia, mas principalmente como um fator preditivo de sua evolução. Porém, outros estudos dedicados ao assunto ainda são necessários no contexto nacional para o desenvolvimento da pesquisa científica e da prática profissional em psicoterapia.

\section{Referências}

Ceitlin, L. H. F., \& Cordioli, A. V. (1998). O início da psicoterapia. In A. V. Cordioli (Org.), Psicoterapias: abordagens atuais (pp. 99-107). Porto Alegre: ArtMed.
Eizirik, C. L., Liberman, Z., \& Costa, F. (1998). A relação terapêutica: transferência, contratransferência e aliança terapêutica. In A. V. Cordioli (Org.), Psicoterapias: abordagens atuais (pp.67-75). Porto Alegre: ArtMed.

Etchegoyen, R. H. (2004). Fundamentos da técnica psicanalítica. Porto Alegre: ArtMed.

Freud, S. (1996a). A psicoterapia da histeria. In J. Salomão (Org.), Edição standard brasileira das obras psicológicas completas de Sigmund Freud (Vol.2, pp.269-316). Rio de Janeiro: Imago. (Originalmente publicado em 1893).

Freud, S. (1996b). Notas sobre um caso de neurose obsessiva. In J. Salomão (Org.), Edição standard brasileira das obras psicológicas completas de Sigmund Freud (Vol.10, pp.135-215). Rio de Janeiro: Imago. (Originalmente publicado em 1909).

Freud, S. (1996c). Sobre o início do tratamento. In J. Salomão (Org.), Edição standard brasileira das obras psicológicas completas de Sigmund Freud (Vol.12, pp.135-158). Rio de Janeiro: Imago. (Originalmente publicado em 1913).

Freud, S. (1996d). Recordar, repetir e elaborar. In J. Salomão (Org.), Edição standard brasileira das obras psicológicas completas de Sigmund Freud (Vol. 12, pp.159-171). Rio de Janeiro: Imago. (Originalmente publicado em 1914).

Gabbard, G. O. (2005). Psicoterapia psicodinâmica de longo prazo: texto básico S.S. Porto Alegre: ArtMed.

Gomes, F. G. (2005). A aliança terapêutica e a relação real com o terapeuta. In C. L. Eizirik, R. W. Aguiar \& S. Schestatsky (Orgs.), Psicoterapia de orientação analítica: fundamentos teóricos e clínicos (pp.246-253). Porto Alegre: ArtMed.

Kernberg, O. F. (2005). Abordagem psicodinâmica das explosões emocionais dos pacientes borderline. In C. L. Eizirik, R. W. Aguiar \& S. Schestatsky (Orgs.), Psicoterapia de orientação analítica: fundamentos teóricos e clínicos (pp.628-645). Porto Alegre: ArtMed.

Laplanche, J., \& Pontalis, J. B. (2000). Vocabulário da psicanálise. São Paulo: Martins Fontes.

Schestatsky, S. S. (2005). Abordagem psicodinâmica do paciente borderline. In C. L. Eizirik, R. W. Aguiar \& S. Schestatsky (Orgs.), Psicoterapia de orientação analítica: fundamentos teóricos e clínicos (pp.606-627). Porto Alegre: ArtMed.

Sterba, R. (1934). The fate of the ego in analytic therapy. International Journal of Psycho-Analysis, 15, 117-126.

Zetzel, E. R. (1956). Current concepts of transference. International Journal of Psycho-Analysis, 37 (4-5) 369-375.

Zetzel, E. R. (1965). The theory of therapy in relation to a developmental modal of the psychic apparatus. International Journal of Psycho-Analysis, 46, 39-52.

Zimerman, D. E. (2001). Vocabulário contemporâneo de psicanálise. Porto Alegre: ArtMed.

Recebido em: 12/2/2008

Versão final reapresentada em: 2/2/2009

Aprovado em: 5/3/2009 